\title{
DE LOS CARACTERES A LA METAFÍSICA
}

POR

EMILSE BEATRIZ CERSOSIMO

Desvalido en medio de un cosmos técnico, el hombre "con minúscula" vivencia cada vez más el pavoroso sentimiento de haber extraviado su camino. En un universo que parece haber perdido su significado, emergen, desde el oscuro fondo de nosotros mismos, las eternas preguntas sobre lo desconocido, la dimensión de nuestras frágiles naves y su exacta posición en esta odisea.

Ernesto Sábato es de aquellos que trabajan sondeando esa otra realidad. Sus novelas no son búsquedas de nuevas normas sino indagaciones sobre la fatalidad y el destino. Estudiar sus caracteres es entreabrir la puerta de su metafísica.

En ellos el elemento fáctico proviene de la herencia familiar y de la circunstancia social que, sin llegar a un determinismo absoluto, marca a los individuos de manera indeleble. Este psiquismo proyecta sobre sus criaturas

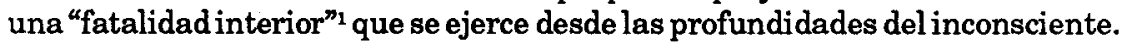
Pero si queremos llegar a realizar un auténtico examen, no habremos de limitarnos a lo psicológico, ya que en Sábatolo psicológico es apenas fundamento de lo metafísico.

La lectura de Sobre héroes y tumbas permite vislumbrar dos tipos de realidades: la diurna o aparencial y la nocturna u onírica. Yésta determina el destino de aquélla. Alejandra termina realizando lo que sus fantasmas interiores le venían sugiriendo a través de su dramático mundo onírico: "Sueño siempre. Con fuego, con pájaros, con pantanos en los que me hundo, o con panteras que me desgarran, con víboras. Pero sobre todo con fuego, al final siempre hay fuego"s.

Estas dos formas de realidad han sido enunciadas por el propio autor en $\mathrm{El}$ escritor y sus fantasmas:

En mi novela pretendí dar a la realidad toda su extensión y profundidad, incluyendo no sólo la parte diurna de la existencia sino la parte nocturna y

${ }^{1}$ Carl Jung, Psicología y poesia en filosofía de la ciencia literaria. Volumen conjunto (México, 1946), 348.

${ }^{2}$ Ernesto Sábato, Sobre héroes y tumbas (Buenos Aires: Cía. Fabril Editora), 119. 
tenebrosa. Y siendo Fernando Vidal el personaje central y decisivo, todo lo que a él se refiriera era importante y debía ser transcripto, muy especialmente aquello que fuera su obsesión fundamental, aunque aparentemente tuviera muy poco que ver con los sucesos luminosos o diurnos. Su informe es la gran pesadilla de Fernando y expresa, aunque sea símbolica y oscuramente, la clave de esa región enigmática donde se hacen y deshacen destinos?.

El surrealismo, escuela que lo subyugó, destacó la importancia de los sueños. Para Breton: "El poeta del porvenir superará la idea deprimente del

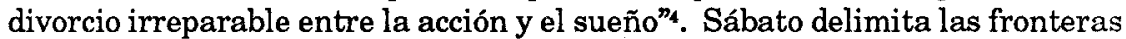
entre la realidad diurna y la nocturna, estableciendo "vasos comunicantes"; los sueños de sus criaturas no sólo muestran sucesos importantes del pasado, sino también son esbozos de acción en el futuro.

El estudio de los caracteres permite observar la interrelación de los aspectos de la realidad. En ellos, lo diurno consistiría en las actitudes y hechos tales como pueden ser captados por un observador inteligente de la realidad aparencial; lo nocturno adquiere dimensiones metafísicas, a través de la psicologia profunda.

La interpretación de los personajes de Sábato resulta difícil, ya que nunca los entrega unívocamente; los hace hablar y obrar en forma indirecta, los muestra tal como otros los ven y nunca nos da en principio su totalidad: los dosifica en la medida en que avanza su novela. Como si tuviéramos que reconstruir un mapa que avanza creándose y recreándose en un río, en este caso el río del tiempo en que el autor sumerge intencionalmente a sus criaturas. Recién al finalizar la lectura comprendemos la importancia de Fernando Vidal: destrozó las vidas de Alejandra y de Georgina, mutiló las existencias de Bruno y Martín y orquestó siniestra y fríamente el destino de muchos que se perdieron para siempre.

Admitidos los dos tipos de realidad, se llega a la realidad aparente de Fernando a través de las evocaciones de Bruno en el cuarto y úl timo "movimiento" de esta novela: $A$ un Dios desconocido. Casi adolescente, vive en una mansión corroída. Lo acompañan sus primos: Bebe, un idiota que toca el clarinete, y Georgina, dulce y maternal. Recién traspuesto el umbral de la infancia los tres viven con total indiferencia de los adultos que habitan el resto de la casa (la tía María Teresa, el bisabuelo Pancho y los abuelos de Fernando), a quienes el autor apenas alude, sugiriendo de esta manera un grave y mutuo desapego afectivo. Bruno recuerda muy bien las características enfermizas del carácter de Fernando: "Fernando odiaba a su padre. Por aquel tiempo tendría doce años y era moreno y duro como él"s.

La inclinación patológica hacia la madre, Ana María, determina sus relaciones con Georgina, que la recuerda:

\footnotetext{
${ }^{3}$ Ernesto Sábato, El escritor y sus fantasmas (Buenos Aires: Aguilar 1963), 19.

${ }^{4}$ Maurice Nadeau, Historia del surrealismo (Buenos Aires, 1948), 34.

${ }^{5}$ Ernesto Sábato, Sobre héroes y tumbas, 424.
} 
Georgina se parecía asombrosamente a Ana Maria: no sólo por sus rasgos físicos como Alejandra, sino y sobre todo por su espiritu: era algo así como la quintaesencia de la familia Olmos ... 6 .

La "fatalidad interior" actúa sobre la base de traumas ocurridos en zonas remotas de la infancia. El conflicto triangular padre-madre-hijo, bajo la forma de memoria inconsciente, hace que en toda relación amorosa necesite del padecimiento de un tercero. En su adolescencia fue Bruno; posteriormente, en sus relaciones con la ciega, necesitó la presencia física del ciego paralítico; en su tragicómico matrimonio, los celos alternativos de Szenfeld, Shapiro y la madre de su esposa; con Norma Pugliese, la ambigua figura de la señorita González Iturrat.

Estamos observando el desplazamiento en el tiempo de una enfermedad mental en la que el protagonista repite sin saberlo canales torcidos de conducta generados en la infancia. Fernando, identificándose inconscientemente con el padre (al que se parece), orquesta como sonámbulo sus relaciones, como sumo sacerdote de un culto atroz, en el que siempre será imprescindible que la serpiente de los celos envenene a alguien.

$Y$ no sólo en forma privada se repite ese conflicto infantil. También socialmente, cuando en su juventud capitaneaba bandas de asaltantes y anarquistas, la autoridad paterna era sustituida por la social, el idealismo anarquista por el delito común.

Bruno, inteligente observador de la realidad diurna, advierte en Fernando rupturas de la personalidad: "siempre pensé que en él habitaban varias personas diferentes"

El propio Fernando habla de estas divisiones en El informe sobre ciegos:

No sé lo que pasará con los otros. Yo sólo puedo decir que en mí esa identidad de pronto se pierde y que esa deformación del yo de pronto alcanza proporciones inmensas .... ${ }^{8}$.

Y porque muchos de los episodios que relataré, de otro modo serían incomprensibles e increbles. Pero pasaron en buena medida gracias a esa ruptura catastrofica de mi personalidad; no a pesar de ella, sino precisamente gracias a ella?.

Vastas zonas de su vida permanecerán en sombras. De vez en cuando, informaciones de Bruno permiten percibir algunos rasgos de su personalidad aterradora, acentuándose de esta manera la densidad crepuscular que lo rodea. Sus viajes son misteriosos y constantes, sus inclinaciones y compañias, turbias.

Su retrato, tal como lo ve Bruno, corresponde al de un perverso:

\footnotetext{
${ }^{6}$ Ibidem, 414.

${ }^{7}$ Ibidem, 411.

'Ibidem, 271.

' Ibidem, 272.
} 
Si un hombre tiene su más auténtico rostro cuando está en soledad, el más auténtico rostro de Fernando era despiadado y cruel, como tallado a cuchillo ${ }^{10}$.

Sobre esta máscara, es capaz de organizar las más perfectas imitaciones de los más nobles sentimientos. No es capaz de amar y él mismo lo manifiesta en El informe sobre ciegos:

No tengo ni he tenido nunca amigos, he tenido pasiones, naturalmente, pero jamás he sentido afecto por nadie, ni creo que nadie lo haya sentido por $\mathbf{m i}^{11}$.

El odio por un remoto rechazo materno lo ha convertido en un corruptor de mujeres que experimenta placer en degradarlas. La aventura con Norma Pugliese, contada con cinismo, abunda en expresiones de goce frente a la perversión que desencadena: "El placer que experimentaba en corromper a la maestra"12.

Psicópata, corruptor, desprovisto de afectos y cínico. Tal el retrato diurno y aparencial de Fernando; pero detrás de la realidad exterior, existe otra más profunda, captada por los demás personajes mediante una intuición inconsciente. Cuando Martín lo ve, lo encuentra dotado de una "tenebrosa belleza"13. Bruno, al hablar de sus relaciones con Georgina, lo nombra varias veces como "demonio"14.

Al abrirse la gran fauce del infierno, que es El informe sobreciegos, mediante extraños símbolos y desgarradas imágenes, Sábato transmite una noción de la naturaleza del mal. Superficialmente una enfermedad mental; profunda y esencialmente, un laberinto regido por el odio.

Dante imagina su infierno en círculos: los más amplios corresponden a los pecados más leves; en la medida en que sus condenados son más y más perversos los círculos se van estrechando hasta la casi absoluta desaparición del espacio, la carne es reemplazada por la piedra o el hielo, y en el círculo donde reside el príncipe de las tinieblas más poderoso la inmovilidad es absoluta y letal.

La estructura del infierno sabatiano es circular. Fernando, perseguidor de ciegos, se encuentra varias veces perseguido por ellos. Corrompe a Norma Pugliese para que le sirva de instrumento en su averiguación, pero, llegado el momento, sospecha de la maestra y piensa si acaso no será un instrumento de la secta para vigilarlo:

¿Por qué Norma me había traído a la señorita González Iturrat? Tampoco podía ser una simple coincidencia la discusión que me obligaron a mantener sobre la naturaleza del mal. Pensándolo bien, encontré que la profesora tenía todas las características de una socia de la biblioteca para ciegos. Y la sospecha se extendió a la propia Norma Pugliese ${ }^{15}$.

\footnotetext{
${ }^{10}$ Ibidem, 453.

11 Ibidem, 272.

12 Ibidem, 285.

${ }^{13}$ Ibidem, 239.

14 Ibidem, 430.

${ }^{18}$ Ibidem, 296.
} 
Cronológicamente, la aventura con la ciega en el taller de Domínguez es anterior a la persecución que inicia en Buenos Aires El informe sobre ciegos. Cuando cree descubrir que la ciega y su marido, a quienes vigilaba, en realidad son cómplices y lo están vigilando a él, huye por todo el mundo, de manera que su primer círculo es amplísimo. Posteriormente persigue y es perseguido en la ciudad de Buenos Aires y cuando llega a la casa de la Recova, luego de una angustiante búsqueda, y se encuentra en la habitación de la ciega, cae en delirio, luego despierta en ese mismo cuarto describiendo su último y más cerrado círculo.

Para Diel ${ }^{16}$, "el laberinto significa el inconsciente, el error y el alejamiento de la fuente de vida". Este es el sentido que consideramos acertado para la interpretación del laberinto sabatiano. Es el inconsciente, puesto que el mismo autor lo puntualiza en El escritor y sus fantasmas ${ }^{17}$, pero no la zona de donde se extrae la fuerza para vivir, sino la potencia irreductible que "posee" y se adueña del hombre. En síntesis: lo infernal.

La paranoia de Fernando instala ese laberinto en el interior de su mente. Concluye siempre perseguido por aquellos a quienes perseguía, como si su estructura mental fuera la de una serpiente que se muerde la col $\mathbf{a}^{18}$. La despiadada exploración del inconsciente abismal de Fernando nos conduce a la conclusión de Baudelaire:

El cerebro bien conformado lleva en sí dos infinitos, el cielo y el infierno, y en cada una de estas imágenes el hombre se reconoce a sí mismo ${ }^{10}$.

\section{LA IDENTIFICACION}

Es este un fenómeno psicológico que puede dar origen al amor. Pero cuando el individuo es neurótico produce la pérdida de la personalidad, o para decirlo en términos de la dialéctica de Jung, "pérdida de laindividuación ${ }^{20}$. En los ciegos, Fernando ve la encarnación del mal; Satanás reina en la tierra por intermedio de "La Secta" que supone posee diferentes jerarquías, así como los teólogos creen que las hay en los cielos y el infierno. Apasionado en investigar la naturaleza del mal, se define a si mismo como un canalla y en repetidas ocasiones exclama: "Soy un canalla porque saben que soy uno de ellos"21.

Lenta en principio, la identificación se intensifica hacia el final, cuando las entidades que persigue terminan poseyéndolo para siempre. En el capítulo XX,

\footnotetext{
${ }^{16}$ Paul Diel, Le symbolisme dans la Mytologie Grecque. Paris, 1952, 369.

${ }^{17}$ Ernesto Sábato, El escritor y sus fantasmas (Buenos Aires: Aguilar 1963), 19.

${ }^{18}$ El círculo, representado varias veces con la imagen del dragón mordiéndose la cola, es para los gnósticos uno de los símbolos del tiempo. (Eduardo J. Cirlot, Diccionario de stmbolos (Barcelona: Labor, 1969).

${ }^{19}$ Jean Paul Sartre, Baudelaire (Buenos Aires, 1969), 28.

${ }^{20}$ Carl G. Jung, El yo y el inconsciente (Buenos Aires, 1964), 130.

${ }^{21}$ Ernesto Sábato, Sobre héroes y tumbas, ed. cit., 301.
} 
Fernando -que recorre la casa de la Recova, horas antes abandonada por Iglesias-, se encuentra tanteando con su bastón blanco, y él mismo apunta como detalle revelador: "me encontré golpeando las paredes como un auténtico ciego ${ }^{\text {n22 }_{2} \text {. }}$

En el capítulo XII, iniciado ya el delirio, un gran pájaro lo enceguece, produciéndose la identificación no sólo por actitud, sino también por similitud. En el capítulo XXVI, es absorbido por la gran diosa siniestra, transfiguración poética del arquetipo de la madre terrible, y así la identificación se transforma en fusión. El anhelo por conocer lo funde con las entidades malignas y de esta manera el perseguidor se transforma en el perseguido. Por esta razón, Fernando, canalla y odiador de los emisarios del mal, encarnados en los ciegos, se transforma en las entidades que siguió obsesivamente.

Es por eso que manejó y destruyó a tantos seres; de allí surge su "tenebrosa belleza", su energía inagotable, su orgullo y soberbia ilimitados.

Si bien la unión con la diosa significa una vuelta al útero, y el contexto permite afirmar que la ciega es Alejandra, el doble incesto está elaborado en forma tal que impone a la consciencia sensible (no racional) del lector imágenes horrorosas, ya que desde los tiempos más remotos la humanidad ha temido a esta clase de relación ${ }^{23}$.

En lenguaje místico, la unión del alma con Dios ha sido asimilada a un matrimonio espiritual. La identificación y fusión de Fernando con los poderes tenebrosos es sexual, con primacía del odio y la violencia. En la medida en que se va realizando, el protagonista se transforma en serpiente, en pulpo, en rata fálica, animales todos de infernales atributos. Violenta y paroxística, esta unión está cargada de odio implacable y mutuo; el paisaje fantástico que acompaña a esta cópula infernal está sacudido por cataclismos, la luna estalla en mil pedazos, en medio del fuego y de la sangre como en un cuadro de Jerónimo Bosco.

El paisaje que rodea a la diosa, en cambio, está presentado con una ausencia total de vida y movimiento. Lugar de torres derruidas, esqueletos de al tas hayas muertas, páramos melancólicos, cordilleras lunares, cráteres apagados. La misma deidad está hecha de piedra. La vida ha desaparecido. La madre terrible ${ }^{24}$, símbolo del lado siniestro de la naturaleza, símbolo de la muerte, está acompañada de un paisaje en el que todo tiene una connotación de ruina o disolución: la luna, para Eliade simboliza "el mundo inferior, mundo de las tinieblas" ${ }^{25}$, o bien símbolo mortuorio, según algunas interpretaciones provenientes del Tarot; los páramos y las pendientes abruptas son índices de

\footnotetext{
${ }^{22}$ Ibidem, 327.

${ }^{23}$ Sobre el temor del incesto véase a Sigmund Freud, Totem y Tabú Obras completas (Madrid, 1948), 419-473.

${ }^{24}$ Carl Jung Transformaciones y símbolos de la ltbido (Buenos Aires, 1961), 293. Destaca la ambivalencia de los símbolos maternos. Para el, "la madre terrible" tiene sentido y figura de muerte.

${ }^{25}$ Mircea Eliade, Tratado de historia de las religiones (Madrid, 1954), 38.
} 
finales apocalípticos, anhelo de dominio y muerte ${ }^{26}$; las torres destruidas, la ruina del anhelo de elevación del hombre?

A esta degradación de la materia corresponde una degradación en el espíritu. A medida que Fernando asciende en las entrañas de la diosa, desciende en su condición, regresa a etapas pre-humanas:

Mi cuerpo se iba convirtiendo en el cuerpo de un pez. Mis extremidades se transformaban repugnantemente en aletas, y sentí que mi piel se cubría de duras escamas ${ }^{28}$.

Al culminar la identificación con los poderes malignos, lo humano se va transformando en bestial. Pero los condenados de Dante, nos dice Francisco de Sanctis, "tienen el apetito y el instinto de la bestia, tienen la consciencia del hombre ${ }^{\boldsymbol{x}_{29}}$. Un matiz diferente aparece en el infierno sabatiano. Conciencia y conocimiento se animalizan:

Mi cuerpo-pez apenas podía deslizarse por aquel agujero, ya no subia por mi propio esfuerzo, pues meera imposible mover las aletas: poderosas contracciones del aquel angustioso túnel me llevaban con incontenible fuerza de succión, hacia el extremo alucinante. Hasta que de pronto perdí el conocimiento-pez ${ }^{30}$.

La inteligencia, último baluarte de esta atormentada entidad, apaga sus destellos finales. En la ancestral lucha espíritu-materia parece haber triunfado para siempre la materia, imponiendo su taciturno sello de muerte.

Detrás de esta aterradora metáfora, vibra en la conciencia sensible del lector la esencia de lo demoníaco. No se trata de darnos (sería contrario al quehacer artístico) una versión dialéctica, discursiva de la naturaleza del mal. El artista lo recrea haciendo sentir sus siniestros aletazos, inexorable, irreductible a dimensión racional.

De todas maneras, y a través del universo que Sábato presenta, se le pueden señalar bases activas a través de las que se proyecta:

1) El mal es divorcio absoluto entre la inteligencia y la sensibilidad: Fernando, hombre inteligente, no fue nunca capaz de amar.

2) El odio es su elemento de vanguardia: el que odia se transforma en el objeto de su odio, según pudimos observar en el proceso de identificación de Fernando con los poderes tenebrosos.

3) Es fuerza involutiva: Fernando regresa a un anti-nacimiento.

4) Su imagen sensible es un laberinto circular regido por el odio.

${ }^{26}$ Juan E. Cirlot, Diccionario de stmbolos, 297.

${ }^{27}$ Ibidem, 393.

${ }^{28}$ Ernesto Sábato, Sobre héroes y tumbas, 388.

${ }^{28}$ Francisco De Sanctis, Las grandes figuras poéticas de la divina comedia (Buenos Aires, 1945), 217.

${ }^{30}$ Ernesto Sábato, Sobre heroes y tumbas, 389. 
5) Es muerte y destrucción.

6) Es la sórdida solidez de la materia desespiritualizada.

7) Está colocado en el camino del hombre para causar dolor y probarlo. Cuando se resiste a la prueba, la humanidad se espiritualiza más, como sucede con Bruno y Martín.

En cuanto a Fernando como carácter, sus aspectos paranoicos recuerdan la psicología de Hitler, según el análisis efectuado por Fromm ${ }^{31}$. Peroen sus delirios resulta increible. En la realidad diurna es un loco, en la realidad profunda u onírica es una fuerza cósmica.

\section{EL MITO: ELEMENTOS CLASICOS}

Mito y literatura "se funden en la zona ambigua y oscuramente nebulosa en que el hombre entra cuando trata de encontrar sentido a las cosas de la vida" ${ }^{32}$. Mientras nuestro mundo de hoy, gobernado por técnicos e ingenieros, barre con la dimensión humana de las cosas, los artistas ciertos tratan de entregarnos "la realidad de las cosas a través del hombre ${ }^{\text {ᄁss }}$. Toda auténtica literatura busca coherencia, y esta sólo puede hallarse "dentro de una mitología subyacente ${ }^{{ }^{34} \text {. }}$ Oscuramente, en la obra de Sábato reina el mito. Su novela adquiere dimensiones de cosmología y, en el personaje que encarna las fuerzas del mal y la disolución, reitera el mito de Edipo. Es obvio recordar que el héroe antiguo - desconociendo su origen - mata al padre y desposa a la madre. Fernando odia al padre "al que intentó envenenar ${ }^{355}$, y se siente enfermizamente atraído por la madre. Un ciego arrojará sobre Edipo su trágica y desconocida verdad. Los ciegos ponen en contacto a Fernando con una realidad atroz: como Edipo, él también concluirá enceguecido. Este parentesco ha sido advertido ya, entre otros, por la profesora Angela Dellepiane ${ }^{36}$. Un encuentro con el mito griego, prescindiendo de la literatura, sería imposible como ya lo dijo Eliade:

Los mitos griegos clásicos, representan el triunfo de la obra de arte sobre la creencia religiosa. No disponemos de ningún mito griego transmitido con su contexto cultural ${ }^{37}$.

En un autor como Sábato, en el que la noche y lo onírico adquieren dimensiones sobrecogedoras, el análisis de las concomitancias y divergencias

\footnotetext{
${ }^{31}$ Erich Fromm, El corazon del hombre. México, 1966, 109-133, y el breve análisis de Merlo y Saussure. Psicoanalisis de Hitler, Buenos Aires, 1957.

${ }^{32}$ Marcelino Peñuelas, Mito, literatura y realidad (Madrid, 1965), 130.

${ }^{33}$ Ibidem, 133.

${ }^{34}$ Ibidem, 135.

${ }^{36}$ Ernesto Sábato, Sobre heroes y tumbas, 413.

${ }^{36}$ Angela Dellepiane, Ernesto Sábato, el hombre y su obra (Nueva York, 1968).

${ }^{37}$ Mircea Eliade, Mito y realidad (Madrid, 1968), 176.
} 
entre su particular comprensión de la realidad y la de un clásico confieren a su obra una inesperada luminosidad.

De todas maneras, $y$ antes de entrar en la comparación, resulta necesario señalar que la posición que la sociedad confería al poeta de la antigua Grecia es la misma que Sábato otorga al creador actual. La religión griega no era un cuerpo fijo de doctrina, el espectador ateniense del siglo $V$ no concurría al teatro para ver desenvolverse ante él un argumento: lo conocía y su actitud era la del hombre que busca aprender a conocerse a si mismo y a sus relaciones con el mundo de los dioses ${ }^{\text {s8. }}$.

A propósito de la literatura del siglo XX afirma Sábato:

...la literatura ha adquirido una nueva dignidad, a la que no estaba acostumbrada: la del conocimiento. Pues mientras se creyó que la realidad debía ser aprehendida por la sola razón, la literatura parecia relegada a una tarea inferior, heredera vergonzante de la mitología y de la fábula, actividad tan adecuada a la mentira como la filosof́a y la ciencia de la verdad. Pero cuando se comprendió que no toda la realidad era la del mundo físico, ni siquiera las especulaciones sobre la historia y las categorias; cuando se advirtio que tambien formaban parte de la realidad ( $y$ en lo atinente al hombre de manera capital) los sentimientos y las emociones, entonces se concluyo que las letras eran un instrumento de conocimiento, y acaso el único capaz de penetrar en el misterioso territorio del hombre con minúscula ${ }^{39}$.

\section{LOS PLANOS DE LA REALIDAD. LA FATALIDAD}

Apolo había decretado la destrucción del rey de Tebas aún antes de haber sido engendrado por Layo. Lo sabía el espectador ateniense que lo veía agitarse en medio de su absurdo esplendor de rey-salvador de su pueblo. Transcurría el drama en dos planos: el aparencial y el de los dioses.

Cuando Edipo descubre su verdadera identidad, y de rey amado pasa a ser el más desventurado de los hombres, la realidad divina irrumpe en el mundo aparencial de los humanos aniquilando la ilusión y produciendo lo que Aristóteles denomina la pericia y el reconocimiento.

En Sobre héroes y tumbas, y particularmente en el personaje central, se dan estos dos planos de la realidad, pero las potencias oscuras que decretan la desaparición y extinción de Fernando se encuentran instaladas en la mente del personaje. Son los planos que el Sábato dialéctico denomina "realidad diurna" $\mathrm{y}$ "realidad onírica". Su arte vuelve tangibles (la deidad de piedra) las entidades espirituales, que surgen del corazón-mente, del carácter "central y decisivo".

Nada podía hacer Edipo frente a una fatalidad que le era absolutamente ajena y de la cual creía haberse liberado por medio de su voluntad inteligente.

\footnotetext{
${ }^{38}$ Para el análisis de la tragedia de S6focles nos hemos basado en la monografía de Eilhard Schlesinger. El Edipo rey de S6focles. La Plata, 1950.

${ }^{39}$ Ernesto Sábato, El escritor y sus fantasmas, 369.
} 
Fernando reconoce que es imposible liberarse, pero ve en ella una creación interna:

La astucia, el deseo de vivir, la desesperacion, me han hecho imaginar mil fugas, mil formas de escapar a la fatalidad. ¿Pero cómo nadie puede escapar a su propia fatalidad? ${ }^{40}$.

Dos tipos de realidad para Sófocles: divina y humana. Dos realidades en Sábato: onfrica y diurna. El destino decretado desde la esfera divina para Sófocles; el destino surgiendo de la esfera onírica, para Sábato.

\section{FUSION DE LAS DOS REALDADES. LA IRONIA}

Cuando Edipo maldice al causante de la peste, cuando afirma que vengará a Layo como si se tratara de su padre, cuando se acerca a Yocasta para confiarle la congoja que lo perturba, manifestando: "a quién sino a ti", la realidad divina y la humana quedan soldadas aún a despecho de la serena inconsciencia de Edipo, produciéndose lo que los teóricos del teatro denominan "ironía trágica".

Fernando busca obsesivamente un encuentro con una estructura tenebrosa e ilimitada de la realidad, pero, hasta los momentos previos a su identificación, su conciencia tiene límites; por eso se producen desgarramientos en su personalidad:

La gente no comprendía lo que me pasaba, me veía concentrarme con mi mirada fija y ajena, y creía que me estaba volviendo loco, sin comprender que era al revés, precisamente al revés, puesto que merced a ese esfuerzo lograba mantener a la realidad en su sitio y en su forma ${ }^{41}$.

Los comentarios de Fernando sobre el mundo cotidiano, mueven a risa. Pero de pronto esa risa puede transformarse en mueca de angustia:

Al salir del bar, y después de mi visita nocturna a la pensión, sobre Plaza Once, contemplaba el gran cartel que anuncia los fideos Santa Catalina; no me parecía dificil que hubiese sufrido el martirio, ya que el martirio fue casi siempre el fin profesional de los santos; y entonces no podía dejar de meditar sobre esa caracteristica de la existencia humana consistente en que aún crucificado o aún desollado vivo, con el tiempo, se convierte en una marca de fideos o de conservas en lata ${ }^{42}$.

Mediante el uso de las mayúsculas, el autor desconcretiza elementos de la realidad ‘s. Así, en la descripción nocturna de la zona de los bancos, ciertas

\footnotetext{
${ }^{40}$ Ernesto Sábato, Sobre heroes y tumbas, 396.

41 Ibidem, 270.

42 Ibidem, 288.

${ }^{43}$ Raúl Castagnino, "Lo abstracto y lo concreto en el estilo". El análisis literario.
} 
palabras escritas con mayúscula (Crédito, Dinero, Oficina, Fiduciario) se imponen a la conciencia bajo una máscara enigmática y siniestra:

El silencio y la soledad tenían esa impresionante vigencia que tienen siempre de noche en el barrio de los Bancos. Barrio mucho más silencioso y solitario, de noche, que cualquier otro; probablemente por el contraste, por el violento ajetreo de esas calles durante el día; por el ruido, la inenarrable confusion, el apuro, la inmensa multitu due alli se agita durante las horas de Oficina. Pero también con certeza, por la soledad sagrada que reina en esos lugares cuando el Dinero descansa".

El recuerdo de Kafka es quizá inevitable.

Producidos los delirios que loidentifican con las potencias del mal, Fernando duda de la realidad aparencial -a la que confiere menos importancia que a la profunda-o, para decirlo con los términos de la dialéctica de Sábato, de la realidad nocturna.

Enceguecido y sordo, como un hombre que emerge de las profundidades del mar, fui surgiendo nuevamente a la realidad de todos los días. Realidad que me pregunto si al fin es la verdadera ${ }^{45}$.

Edipo, en cambio, no duda de la realidad profunda ni de la voluntad de los dioses, una vez llegado su reconocimiento. En el héroe antiguo no hay culpa ni temor al castigo, mientras que Fernando, culpable cósmico, se sabe predestinado al fuego. La ironía trágica en Sófocles proviene de la fusión de las dos realidades en el plano de la contemplación estética, sin que los personajes adviertan esa integración. Sin haber conocido la esperanza, Edipo (y con él el mundo antiguo) tampoco conocía la desesperación. La idea de culpa le era ajena. El error de Edipo no se encuentra en el parricidio ni en el incesto, colocados fuera de la tragedia en Sófocles; y que en Aristóteles tampoco tenían connotación de culpabilidad ${ }^{46}$, ya que ocurrían contra su voluntad. En Sábato la culpabilidad va emergiendo a través de significativos pasajes de el Informe sobre ciegos:

Yotro día, abriendo al azar el gran volumen de mitologia de mi madre leí: $Y$ yo, Tiresias, como castigo por haber visto y deseado a Palas Atenea mientras se bañaba, fui enceguecido; pero apiadada la Diosa me concedio el don de comprender el lenguaje de los pájaros proféticos; y por eso te digo que tú, Edipo, aunque no

\footnotetext{
44 Ernesto Sábato, Sobre héroes y tumbas, 259.

45 Ibidem, 396.

${ }^{46}$ Aristóteles. Poética. Cap. XIII. "Queda pues el caso de quien se encuentra en medio de ambas situaciones. Tal el que no descuella en virtud ni en justicia, ni tampoco por maldad o perversión sino por alguna falla; uno de los que se encuentran con suma gloria y felicidad como Edipo y Tiestes y los varones famosos de semejantes linajes".
} 
lo sabes, eres el hombre que mató a su padre y desposó a la madre, y por eso has de ser castigado ${ }^{47}$.

Esta lectura realizada en la infancia lo conmovió de tal manera que su recuerdo reaparece cuando inicia el delirio que lo llevará a la muerte. Aquellas aves predecirán el destino de destrucción de Edipo y también el suyo, el de Fernando Vidal Olmos. Por eso de niño inicia aquella mania aterradora testimoniada por Bruno:

Había apresado un gorrión, lo llevó a aquella pieza que tenía arriba, a la que llamaba fortín, y con una aguja le pinchó los ojos ${ }^{48}$.

Con esta obsesión mecánica, circular, trata de evitar que se descifre su trágica verdad, que se le prediga su ineludible destrucción. Porque aunque su conciencia lo niegue, se "sabe" culpable de haber deseado a su madre. Esta imagen reaparece cuando desciende al infierno, las abominables cloacas de Buenos Aires, en busca de lo que llama el misterio central de la existencia:

Sentí entonces, supongo que en sueños, el rumor del arroyo Las Mojarras al golpear sobre las toscas, en la desembocadura del río Arrecifes, en la estancia del Capitán Olmos. Yo estaba de espaldas sobre el pasto, en un atardecer de verano, mientras ó́a a lo lejos, como si estuviera a una distancia remotisima, la voz de mi madre que, como era su costumbre, canturreaba algo mientras se bañaba en el arroyo. (El subrayado es nuestro) ${ }^{49}$.

Este delirio corresponde a un recuerdo censurado. Como Tiresias, ha deseado a quien no debió y recibirá un castigo. Pero a diferencias de Tiresias, castigado por el capricho de una diosa, él es culpable.

Sorprendido como el ciego, escucha:

ese canto que parecía más alegre al comienzo pero que luego se fue haciendo para mí más angustioso: deseaba entenderle y a pesar de mis esfuerzos no lo lograba, y asími angustia se hacia más insufrible por la idea de que las palabras eran decisivas: cosa de vida o muerte. Me desperté gritando: iNo puedo entender! ¡No puedo entender! ${ }^{\mathrm{s} o}$.

En este sueño está la clave de la locura de Fernando. En su relato desliza alusiones que traicionan su versión de los hechos. Dice haber oído el canto "como si estuviera a una distancia remotísima": en la oración condicional está implícita la aproximación de Fernando a Ana María; y luego afirma que "eran decisivas, cosa de vida o muerte" (notemos que aquí ya no habla de canto).

\footnotetext{
47 ErnestoSábato,Sobre héroes y tumbas, 381.

48 Ibidem, 424.

49 Ibidem, 378.

so Ibidem, 379.
} 
¿Cuáles fueron aquellas palabras decisivas de Ana María? ¿Acaso la madre, de igual manera que la diosa, lo maldijo? Fernando, como la humanidad, ha sido arrojado a la fatalidad por una culpa ligada al sexo y al ansia de conocer ${ }^{51}$. Pero él niega su culpa, no la asume. Por eso se despierta gritando "ino puedo entender!". El reconocimiento de su culpabilidad le impondría un nuevo planteo existencial, pero su soberbia impide esa alternativa. Si añadimos a esto su mentalidad circular y su falta de amor que impide salirse de su yo, su tormento puede ser comparado al de las criaturas de Franz Kafka:

Kafka se dirigia a Dios al impetrar misericordia. Era una petición que ni su Josef $K$, ni ningún otro de sus protagonistas jamás pronuncí ni podía pronunciar, puesto que aquellos negaban su culpabilidad. La confesión de la culpabilidad tan sólo es posible a través del tormento y se lleva a cabo al reconocer éste como un sufrimiento justo. Las figuras de Kafka están inmersas en el tormento y tratan por todos los medios de salir de $6 \mathrm{l}^{52}$.

Místicamente ligada a la tradición del antiguo testamento, y literariamente cercana al pensamiento atormentado de Kafka, esta criatura que no puede salir de sí misma es también Edipo, un Edipo del siglo XX que se sabe culpable y niega su culpa, que persigue a una esfinge interior, viva dentro de él, que terminará por devorarlo. Su persecución a los ciegos es inútil, los ciegos están dentro de él; él es también Tiresias, desde el fondo de sí mismo conoce su verdad: culpable.

Es posible interpretar su odio a los ciegos desde una posición psicológica: la lectura de un fragmento en el que aparece Tiresias como acusador y a la vez ejecutor de una acción similar a la que traumatizó a Fernando, desencadena una enfermedad latente. A partir de ese momento el protagonista se deslizará, primero lentamente, luego con inexorable rapidez, hacia la locura.

Consideramos, no obstante, la interpretación, en el acercamiento al mito conforme lo tratara Sófocles. Es Tiresias, el vidente ciego, quien revela a Edipo su verdadera situación. El rey no lo entiende, y supone que existe una conjuración para derrocarlo, en la que estarían mezclados su cuñado Creonte, la misma gente que asesinó a Layo y hasta Tiresias. Equivocado en cuanto a Creonte, acierta cuando piensa en los asesinos de Layo y en Tiresias. Es su verdadero y desconocido ser quien lo derrocará y es la presencia del ciego un anticipo de su destrucción y caída. El trágico griego, en Edipo en Colono hará que el ex rey de Tebas se identifique con Tiresias. En esta segunda tragedia, Edipo, apartado del mundo, como todo ser que conoce subestructuras lúgubres de la realidad, ciego, es vidente y profeta de su pueblo. El odio de Fernando a los ciegos está relacionado con aquella enigmática figura, aliada de las fuerzas inconscientes que han decretado su destrucción.

\footnotetext{
${ }^{51}$ La idea de sexo, conocimiento y culpa están ligadas en el antiguo testamento. Por eso dice que "Adán conoció a Eva" cuando inició su vida sexual con ella.

52 Walter Falk, Impresionismo y expresionismo. Madrid, 1963, 203.
} 
Tiresias, a través del libro de mitología de su madre, ha profetizado su castigo. Desde el momento fatal en que Fernando encuentra esa historia, comienza a gravitar en su mente aquella extraña figura: el vidente-ciego que desata los principios de su sistemática exploración.

Aunque cronológicamente comienza en el despuntar de un verano de 1947, psicológicamente es necesario situarnos en el instante crucial de la infancia del protagonista. Y, desde el punto de vista de la estructura metafísica de la novela, la exploración comienza desde el principio de los tiempos, en el alba mítica de la historia:

fue un día de verano del año 1947, al pasar frente a la plaza de Mayo, por la calle San Martín, en la vereda de la municipalidad. Yo venía abstraído, cuando de pronto of una campanilla, una campanilla como de alguien que quisiera despertarme de un sueño milenario (El subrayado es nuestro) ${ }^{63}$.

En pleno delirio, grandes pájaros lo enceguecen y de esta manera se identifica con los ciegos y con Tiresias fundiéndose con aquellas potencias que deseó conocer. Entonces, llega a ser vidente de su destino: "cuando por fin me quemen, recién entonces se convencerán ${ }^{n_{\mathrm{s}}}$.

En esta segunda etapa de su experiencia, su identificación puede ser considerada paralela a la de Sófocles en Edipo en Colono.

De esta manera, el carácter "central y decisivo" de Sobre héroes y tumbas retoma con intensidad la antigua tradición. Oscuras fuerzas que decretan la destrucción están en manos de los ciegos. Los violentos, inescrutables dioses del sueño y de la muerte, tienen como emisarios infernales a seres cuyos ojos han vaciado sus cuencas para la realidad cotidiana, pero están dirigidos hacia abismos en los que el hombre se "ve" culpable y destinado a la muerte.

\footnotetext{
${ }^{\text {ss }}$ Ernesto Sábato, Sobre héroes y tumbas, 255.

${ }^{54}$ Ibidem, 54.
} 